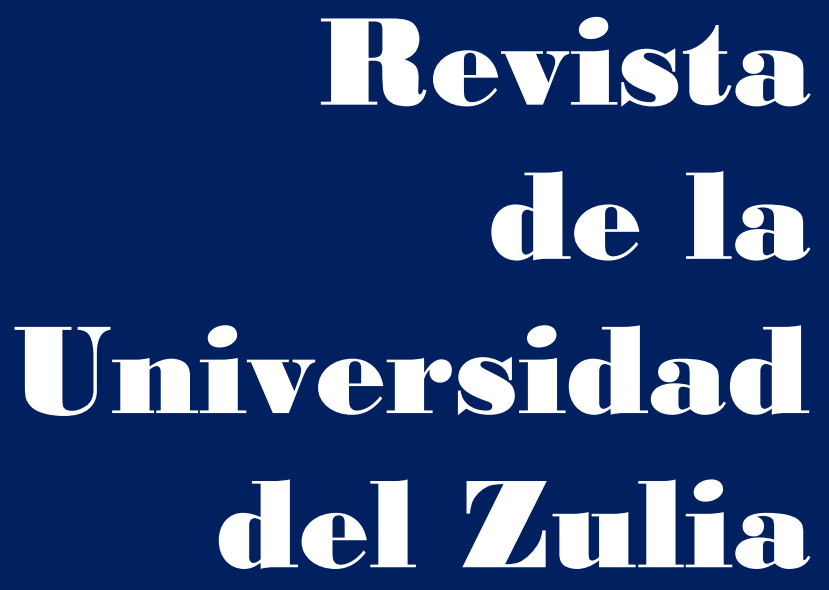

Fundada en 1947

por el Dr. Jesús Enrique Lossada

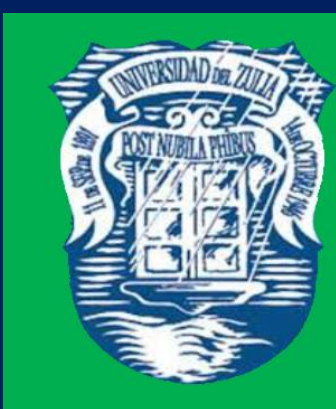

Ciencias del

Agred

Ingemieria

y Teenología
Añต 12 No 32

Enero - Abril 2021

Tercera Época

Maracailbo-Venezuela 


\title{
Calidad físicoquímica y microbiológica del agua en los lagos de Tunants y Yahuahua, en la región Amazonas, Perú
}

\author{
Eli Morales Rojas* \\ Edwin Adolfo Díaz Ortiz** \\ Ligia García *** \\ Jaris Veneros Guevara**** \\ Segundo Chavez Quintana $* * * *$ \\ Cesar Augusto Medina Tafur******
}

RESUMEN

El objetivo de la presente investigación fue caracterizar el agua de los lagos de las comunidades nativas, Tunants y Yahuahua. Con la finalidad de conservar el ambiente acuático para su potencial uso ecoturístico. Estos están localizados en la provincia de Condorcanqui, Amazonas, Perú. Se establecieron dos puntos de muestreo, uno por cada lago, las evaluaciones se realizaron en la temporada lluviosa. Se evaluaron parámetros fisicoquímicos y microbiológicos. Los principales resultados expresan un $\mathrm{pH}$ de 7 para ambos lagos. Con respecto a la $\mathrm{DBO}_{5}$, en el lago de Tunants la mediana se encontró en $1.8 \mathrm{mg} / \mathrm{L}$ de $\mathrm{O}_{2}$ y el lago de Yahuahua la mediana se encuentra entre $1.45 \mathrm{mg} / \mathrm{L}$ de $\mathrm{O}_{2}$. Éstos se correlacionan fuertemente de forma negativa con los sulfatos. Con respecto a los metales pesados la mayor concentración fue el Zinc 0.0375 ppm correspondiente al lago de Yahuahua. El análisis microbiológico mostró una concentración de coliformes totales (CT) >1600 NMP/100mL.

PALABRAS CLAVE: Caracterización del agua, lagos, comunidades nativas, Amazonas.

*Investigador del Instituto de Investigación para el Desarrollo Sustentable de Ceja de Selva (INDES-CES), Universidad Nacional Toribio Rodríguez de Mendoza de Amazonas. ORCID: https://orcid.org/0000-0002-86233192. E-mail: eli.morales@untrm.edu.pe

**Investigador de la Facultad de Ingeniería Civil y Ambiental, Universidad Nacional Toribio Rodríguez de Mendoza de Amazonas, Perú. ORCID: https://orcid.org/0000-0001-7213-9552. E-mail: edwin.diaz@untrm.edu.pe

***Investigadora del Instituto de Investigación, Innovación y Desarrollo para el Sector Agrario y Agroindustrial de la Región Amazonas (IIDAA), Universidad Nacional Toribio Rodríguez de Mendoza de Amazonas. ORCID: https://orcid.org/0000-0001-7508-7516. E-mail: ligia.garcia@untrm.edu.pe

****Investigador de la Universidad Estatal de Montana, Departamento de Ecología. ORCID: https://orcid.org/0000-0001-6981-4078. E-mail: jaris.veneros@untrm.edu.pe

*****Investigador del Instituto de Investigación para el Desarrollo Sustentable de Ceja de Selva (INDES-CES), Universidad Nacional Toribio Rodríguez de Mendoza de Amazonas. ORCID: https://orcid.org/0000-0002-09463445. E-mail: segundo.quintana@untrm.edu.pe

******Investigador del Departamento de Ciencias Biológicas, Universidad Nacional de Trujillo, Trujillo. Perú. ORCID: https://orcid.org/0000-0002-3506-849X. E-mail: cemeta@hotmail.com

Recibido: 12/09/2020

Aceptado: 08/11/2020 


\section{Physical-chemical and microbiological water quality in two lakes of Tunants and Yahuahua, in the Amazon region, Peru}

ABSTRACT

The objective of this research was to characterize the water of the lakes of the native communities, Tunants and Yahuahua. With the aim of conserving the aquatic environment for potential ecotourism use. These are located in the province of Condorcanqui, Amazonas, Peru. Two sampling points were established, one for each lake, and the assessments were carried out during the rainy season. Physical-chemical and microbiological parameters were evaluated. The main results express a $\mathrm{pH}$ of 7 for both lakes. With regard to $\mathrm{BOD}_{5}$, in Lake Tunants the median was found to be $1.8 \mathrm{mg} / \mathrm{L}$ of $\mathrm{O}_{2}$ and in Lake Yahuahua the median is between $1.45 \mathrm{mg} / \mathrm{L}$ of $\mathrm{O}_{2}$. These are strongly correlated negatively with the sulphates. With respect to heavy metals, the highest concentration was Zinc $0.0375 \mathrm{ppm}$, corresponding to Lake Yahuahua. The microbiological analysis showed a concentration of total coliforms (TC) $>1600 \mathrm{NMP} / 100 \mathrm{~mL}$

KEYWORDS: Water quality, Lakes, Communities, Amazon.

Introducción

Del total del agua en el planeta, sólo el 3 \% es agua dulce, que se encuentra en forma de casquetes de hielo y glaciares; y sólo el 1 \% es agua superficial aprovechable (Agudelo, 2005). El agua es un componente importante en la naturaleza por considerarse fuente principal de la vida y la salud. Sin embargo, está siendo alterada por factores antrópicos que suelen ser los principales factores que afectan a la mayoría de los cuerpos de agua, sobre todo para los cercanos a zonas urbanizadas (Kazi et al. 2009; Wen-Cheng et al. 2011). El rápido crecimiento poblacional conjuntamente con las actividades urbanas, agrícolas, pecuarias, forestales, además de las condiciones físicas y químicas del suelo han resultado ser los causantes del deterioro de la calidad del agua (Álvarez, 2008).

Los cuerpos acuáticos naturales y artificiales son sensibles a recibir aguas contaminadas lo que ocasiona impactos negativos en la calidad del agua y la pérdida de diversidad biótica nativa (Luna-Pabello \& Aburto-Casta, 2014; Fernández et al, 2017). Las actividades de mineras de exploración y extracción informal, realizada en forma artesanal generan impacto al medio 
ambiente, evidenciándose concentraciones de mercurio en aguas, sedimentos y peces del río, el riesgo es muy alto para la vida y la salud humana de las zonas amazónicas (Rengifo, 2017).

La calidad de agua está definida por las características fisicoquímicas y microbiológicas (OMS,2006; DS N 004, 2017). Ésta se determina comparando las características físicas, químicas y bacteriológicas del agua con estándares o normativas. Para ello, se mide la concentración de sus componentes y los efectos o propiedades, causadas por la presencia de sustancias químicas inorgánicas que pueden ser nocivas para los seres vivos (PNUMA, 2008).

Entre los indicadores fisicoquímicos están los parámetros de turbidez, pH, la conductividad eléctrica y en cuanto a los indicadores de contaminación orgánica están la demanda bioquímica de oxígeno $\left(\mathrm{DBO}_{5}\right)$, demanda química de oxígeno (DQO), nitrógeno total, entre otros (León, 2006). Los indicadores de calidad microbiológica del agua están influenciados por la presencia de microorganismos indicadores de contaminación fecal como las bacterias coliformes, aunque también pueden encontrarse otros microorganismos patógenos para el humano como Salmonella sp. y Shigella sp., además de virus, bacterias, protozoos y fases enquistadas de metazoarios (Harwood et al., 2005). Siendo las bacterias indicadoras de contaminación fecal más utilizadas son las coliformes totales y termotolerantes. Una enterobacteria de gran importancia es E. coli, ya que su abundancia se ha asociado más al riesgo sanitario en comparación con el resto de los coliformes (Farnleitner et al., 2010).

Los datos fisicoquímicos permiten analizar las causas del problema, pero exigen una frecuencia de muestreo apropiada, pues indican una condición puntual del agua (Ruiz, 2007). Además, está el grupo de índices biológicos de calidad del agua, en los cuales se registra la abundancia y la diversidad de ciertos organismos, especialmente macro invertebrados bentónicos (Madera, 2016). Éstos permiten, a partir de su tolerancia particular a la contaminación, estimar el efecto acumulado de las intervenciones humanas en el ambiente a lo largo del tiempo (Pérez \& Rodríguez, 2008). En ese sentido, se debe contrastar la presencia de contaminantes evaluando variables fisicoquímicas, que permitan definir las condiciones del agua (Pinilla,2000; Dolbeth et al., 2003). Por lo tanto, en áreas con crecimiento poblacional en la región y los problemas de la disponibilidad y la contaminación del agua justifican estudios de caracterización del agua (Gamarra, et al 2018). 
REVISTA DE LA UNIVERSIDAD DEL ZULIA. 3a época. Año $12 \mathrm{~N}^{\circ}$ 32, 2021

Eli Morales Rojas et al. // Calidad físicoquímica y microbiológica del agua en los lagos ... 139-158

DOI: http://dx.doi.org/10.46925//rdluz.32.11

En este trabajo el objetivo fue evaluar la calidad fisicoquímica y microbiológica del agua de los lagos de Tunants y Yahuahua, en dos comunidades de la región Amazonas con los mismos nombres. Actualmente se hace un uso intensivo del agua en ambos lagos, para actividades como la piscicultura y uso doméstico, por lo que la caracterización permitirá por primera vez registrar una data base que permita en lo posterior, establecer estrategias de conservación del ambiente acuático para su potencial uso ecoturístico. Los muestreos se realizaron en los meses diciembre 2019, enero y febrero del 2020.

\section{Materiales y métodos}

El estudio se realizó en los dos principales lagos de las comunidades de Tunants y Yahuahua, pertenecientes al distrito de Nieva, Provincia de Condorcanqui, región Amazonas, Perú. Los Lagos están a una altitud de 2016 m.s.n.m. Así mismo el lago de Tunants (Punto de color rojo) presenta las siguientes coordenadas como referencia espacial: latitud -4.682519 y longitud -78.0220525. De otra manera el lago de Yahuahua (Punto de color verde) posee la siguiente información espacial, latitud -4.678173, longitud -78.015090. Finalmente, estas georreferencias fueron tomadas empleando el GPS GARMIN eTrex 30. A continuación se muestra el mapa de ubicación para los dos lagos (Figura 1).

Ambos lagos están ubicados al borde de la carretera Urakusa-Nieva y a una distancia de 100 metros de las viviendas comunales. Estos son empleados con fines recreacionales y pesca. Los muestreos para los parámetros fisicoquímicos se realizaron una vez al mes, desde diciembre del 2019 hasta febrero del 2020. Seguidamente, se estableció un punto de muestreo por cada lago. La recolección, almacenamiento y traslado de las muestras, así como el análisis de laboratorio se realizaron de acuerdo al APHA, AWWA, \& WEF (2017). Se realizó la toma de datos para el pH de manera in situ, con un medidor de agua multiparamétrico Hanna modelo HI 98194. Las muestras de demanda bioquímica de oxigeno $\left(\mathrm{DBO}_{5}\right)$, conductividad electrica (Ce), turbidez, sólidos disueltos totales (SDT), sólidos suspendidos totales (SST), alcalinidad, dureza, nitratos, nitritos, fosfatos, sulfatos, se procesaron en laboratorio. 


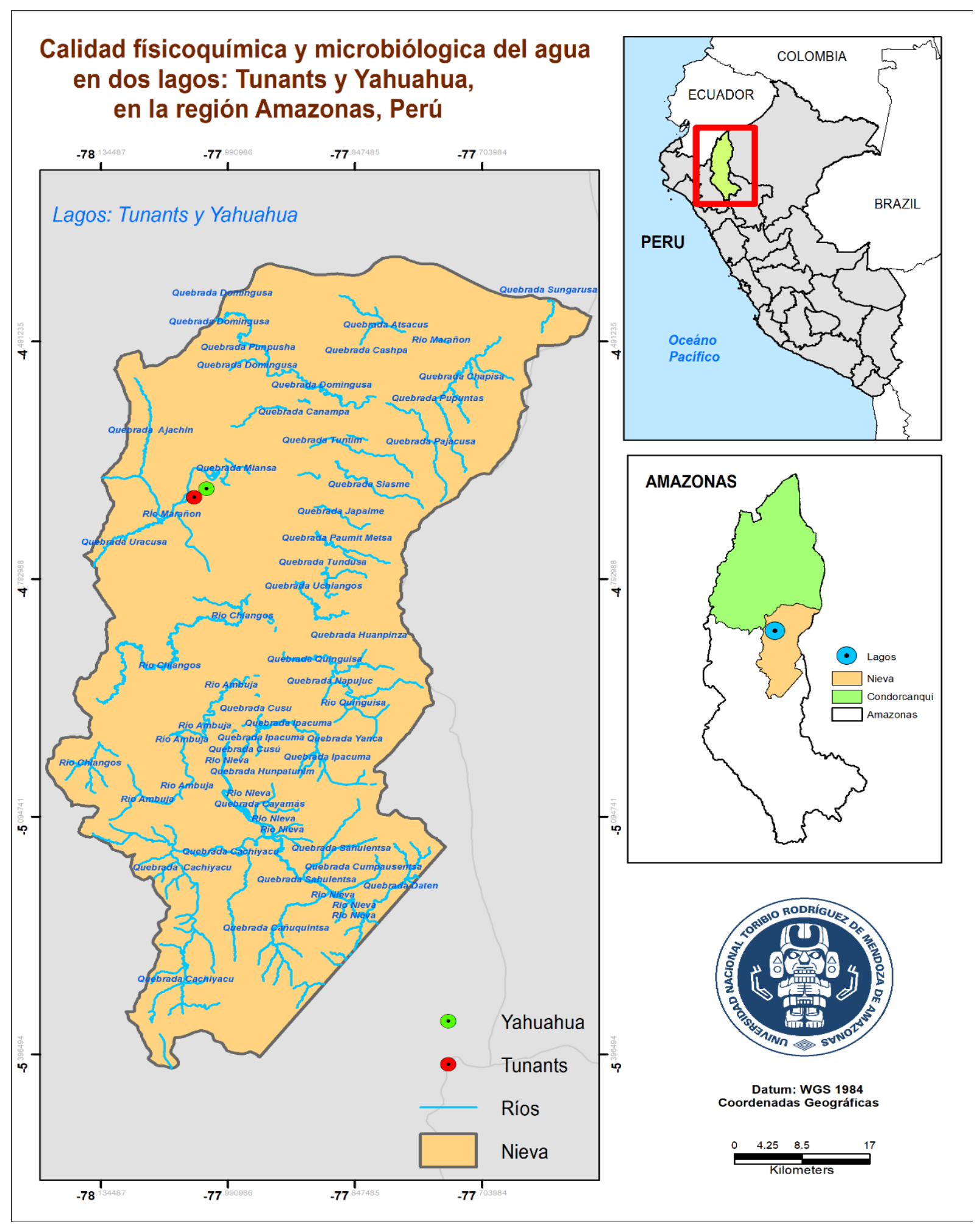

Figura 1. Mapa de ubicación para los lagos Tunants (Lago Número 1) y Yahuahua (Lago Número 2) 
Los parámetros de metales pesados (aluminio, cobre, zinc), se tomaron las muestras dos veces, durante el mes de enero y febrero del 2020. La toma de muestras para el análisis microbiológico, se realizó una vez en el mes de febrero y se midieron los parámetros de coliformes totales (CT), coliformes fecales (CF), Escherichia coli (EC), las muestras se recolectaron en frascos de vidrio con capacidad de $1 / 2$ litro, previamente lavados, enjuagados y esterilizados (RiveraJacinto, 2009). Éstos fueron transportados en un cooler con hielo seco a una temperatura de $5^{\circ} \mathrm{C}$. Los análisis se realizaron en el Laboratorio de Aguas y Suelos del Instituto de Investigación para el Desarrollo Sustentable de Ceja de Selva (INDES-CES) de la Universidad Nacional Toribio Rodríguez de Mendoza. Todos los parámetros fueron comparados con la Categoría 4: Conservación del ambiente acuático, de los estándares de calidad del agua. Del decreto Supremo $\mathrm{N}^{\circ}$ 004-2017-MINAM.

\subsection{Análisis de datos}

El análisis de datos se realizó mediante un análisis gráfico de cajas y bigotes de cada parámetro por punto de muestreo, para mostrar el comportamiento de los parámetros en cada lago y la correlación de los mismos. Todos los análisis estadísticos se realizaron a un nivel de significancia de p<0.05 con el programa estadístico R v. 3.6.3 (R Core Team, 2020).

\section{Resultados}

\subsection{Caracterización de los parámetros fisicoquímicos en los lagos}

Los valores para los parámetros de potencial hidrógeno $(\mathrm{pH})$, turbiedad, conductividad eléctrica (CE) y sólidos disueltos totales (SDT), para los lagos de Tunants y Yahuahua, se presentan en las Figuras 2, 3 y Tabla l. Respecto al pH, para el lago de Tunants, la mediana reportó un valor de 7.10 ( $\mathrm{CV}=2.28 \%$ ). Mientras que para el lago de Yahuahua el $\mathrm{pH}=7$ corresponde a la mediana ( $C V=17.93 \%)$. De igual manera, la mediana para la turbidez en ambos lagos es de 7 UNT (CV= 49.16\% en lago Tunants y CV=39.93 \% en el lago Yahuahua). El lago de Tunants presentó una conductividad eléctrica con un valor de la mediana de $60 \mu \mathrm{S} / \mathrm{cm}^{2}(\mathrm{CV}=14.91 \%)$, y para el lago Yahuahua la mediana para CE está en $54.8 \mu \mathrm{S} / \mathrm{cm}^{2}(\mathrm{CV}=17.64 \%)$. Para los sólidos disueltos totales (SDT), en el lago de Tunants se encontró una mediana de $30.5 \mathrm{mg} / \mathrm{L}$ (CV= 37.77 \%). y para el lago de Yahuahua la mediana está en $20.6 \mathrm{mg} / \mathrm{L}(\mathrm{CV}=25.98 \%$ ). 


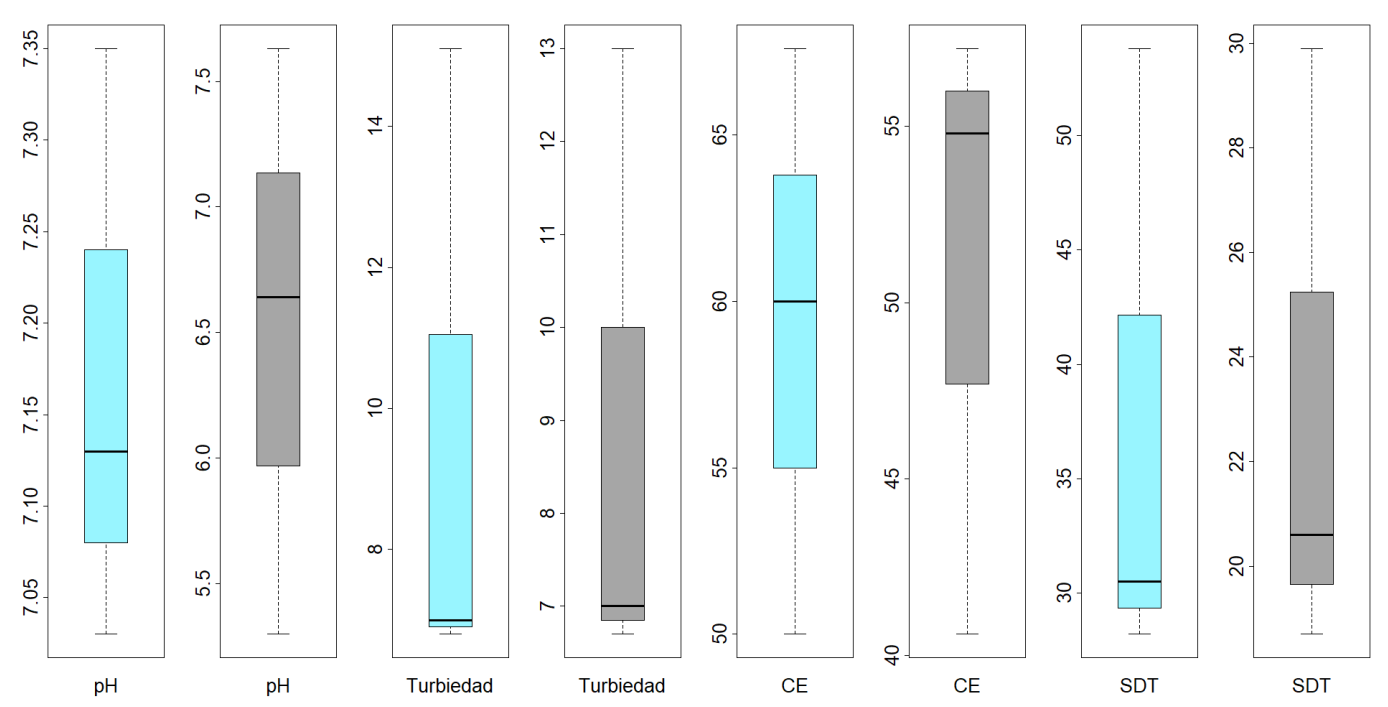

\section{Lago Lago \\ Tunants Yahuahua}

Figura 2. Valores de las medianas de los parámetros pH, turbiedad, Conductividad eléctrica y Solidos totales disueltos, en los dos lagos.

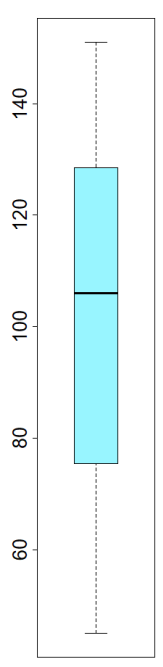

SST
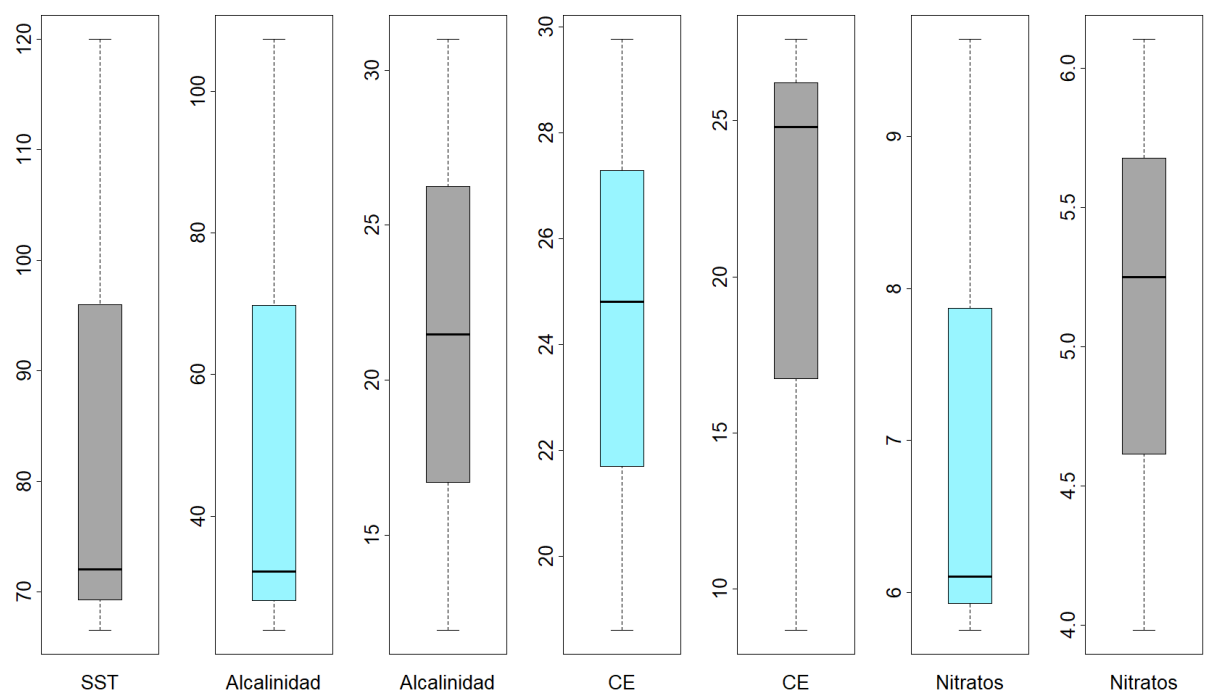

\section{Lago \\ Tunants \\ Lago Yahuahua}

Figura 3. Valores de las medianas de los parámetros SST, Alcalinidad, Dureza, Nitratos, en los dos lagos. 
En la figura 3 encontramos valores de las medianas para los parámetros fisicoquímicos en los lagos de Tunants y Yahuahua. Los Sólidos Suspendidos Totales (SST) para el lago de Tunants arroja una mediana de $106 \mathrm{mg} / \mathrm{L}(\mathrm{CV}=52.85)$, mientras que el lago Yahuahua la mediana arrojó un valor de $72 \mathrm{mg} / \mathrm{L}(\mathrm{CV}=34.15)$. Con respecto a la alcalinidad para el lago de Tunants, la mediana se encuentra en $32.22 \mathrm{ppm} \mathrm{CaCO}_{3}(\mathrm{CV}=84.45 \%)$ y para el lago Yahuahua la mediana está en $21.48 \mathrm{CaCO}_{3}(\mathrm{CV}=44.44 \%)$. La dureza para el lago de Tunants, la mediana se encuentra en 24.48 $\mathrm{mg} / \mathrm{L}(\mathrm{CV}=22.93 \%)$., mientras que para el lago Yahuahua la dureza se encuentra en $24.48 \mathrm{mg} / \mathrm{L}$ $(\mathrm{CV}=50.16 \%)$. Para los nitratos en lago de Tunants, la mediana se encuentra en $6.10 \mathrm{ppm} \mathrm{NO}_{3}$ $(C V=30.02 \%)$. y para el lago de Yahuahua la mediana está en 5.25 ppm $\mathrm{NO}_{3}(C V=20.86 \%)$.

Con respecto a los resultados de los análisis microbiológicos para el lago de Tunants resultó tener mayor concentración de CT, >1600 NMP/100mL, mientras que para el lago Yahuahua tuvo 920 NMP/100mL, de CT. Para los CF el lago Tunants arrojó 350 NMP/100mL, y para el lago de Yahuahua tuvo 920 NMP/100mL. Con respecto a E. Coli el lago de Tunants arrojó un valor de $38 \mathrm{NMP} / 100 \mathrm{~mL}$, mientras que para el lago de Yahuahua arrojó un valor de 28 NMP/100mL. Con respecto a los valores sugeridos por el Reglamento de Conservación del ambiente acuático del DS Nº04-2017-MINAM en su Categoría 4, se encontró que, todas las variables cumplen con la norma establecida; con la excepción de los SST en ambos lagos.

En la figura 4 se observa la mediana para los nitritos en lago de Tunants está 0.03 ppm $(\mathrm{CV}=71.62 \%)$, para el lago Yahuahua la mediana se encuentra en $0.06 \mathrm{ppm}(\mathrm{CV}=89.21 \%)$. Para los fosfatos en el lago de Tunants encuentra en 0.01 ppm $\mathrm{PO}_{4}(\mathrm{CV}=98.92 \%)$; y, para el lago de Yahuahua la mediana se encuentra en 0.03 ppm $\mathrm{PO}_{4}(\mathrm{CV}=65.74 \%)$. Los sulfatos para el lago de Tunants se encontró en 1.9 ppm $\mathrm{SO}_{4}-(\mathrm{CV}=57.52 \%)$. y para el lago de Yahuahua se encontró en $2.5 \mathrm{ppmSO}_{4}(\mathrm{CV}=115.23 \%)$. Mientras que, para la $\mathrm{DBO}_{5}$, en el lago de Tunants la mediana se encuentra en $1.8 \mathrm{mg} / \mathrm{L}$ de $\mathrm{O}_{2}$ y el lago de Yahuahua la mediana se encuentra entre $1.45 \mathrm{mg} / \mathrm{L}$ de $\mathrm{O}_{2}$. 
REVISTA DE LA UNIVERSIDAD DEL ZULIA. 3 a época. Año 12 № 32, 2021

Eli Morales Rojas et al. // Calidad físicoquímica y microbiológica del agua en los lagos ... 139-158 DOI: http://dx.doi.org/10.46925//rdluz.32.11

Tabla l. Resultados de la caracterización de parámetros fisicoquímicos

\begin{tabular}{|c|c|c|c|c|c|c|c|c|c|c|c|c|c|c|c|c|}
\hline \multirow{5}{*}{$\mathrm{Ll}$} & & $\mathrm{pH}$ & Turb & $\mathrm{Ce}$ & SDT & SST & Alcalinidad & Dureza & Nitratos & Nitritos & $\begin{array}{c}\text { Fosfato } \\
\mathrm{s}\end{array}$ & Sulfatos & $\mathrm{DBO}_{5}$ & CT & $\mathrm{CF}$ & E. COLI \\
\hline & $\begin{array}{l}\text { Prome } \\
\text { dio }\end{array}$ & $\begin{array}{c}7.1 \\
7\end{array}$ & $\begin{array}{c}9.6 \\
3\end{array}$ & $\begin{array}{c}59.2 \\
0\end{array}$ & $\begin{array}{c}37.5 \\
0\end{array}$ & $\begin{array}{c}100.6 \\
7^{*}\end{array}$ & 54.49 & 24.39 & 7.16 & 0.03 & 0.01 & 2.37 & 1.42 & \multirow{3}{*}{$>1600$} & \multirow{3}{*}{$\begin{array}{c}35 \\
0\end{array}$} & \multirow{3}{*}{38} \\
\hline & SD & $\begin{array}{c}0.1 \\
6\end{array}$ & $\begin{array}{c}4.7 \\
4\end{array}$ & 8.83 & $\begin{array}{c}14.1 \\
6\end{array}$ & $\begin{array}{c}53.20 \\
*\end{array}$ & 46.02 & 5.59 & 2.15 & 0.02 & 0.01 & 1.36 & 0.65 & & & \\
\hline & $\mathrm{CV} \%$ & $\begin{array}{c}2.2 \\
8\end{array}$ & $\begin{array}{l}49 . \\
16\end{array}$ & $\begin{array}{c}14.9 \\
1\end{array}$ & $\begin{array}{c}37.7 \\
7\end{array}$ & $\begin{array}{c}52.85 \\
*\end{array}$ & 84.45 & 22.93 & 30.02 & 71.62 & 92.82 & 57.52 & 45.84 & & & \\
\hline & $\begin{array}{l}\text { ECA- } \\
\text { C4 }\end{array}$ & $\begin{array}{c}6,5 \\
- \\
9,0\end{array}$ & - & $\begin{array}{c}1 \\
000\end{array}$ & - & $\leq 25$ & - & - & 13 & - & - & - & 5 & 1000 & - & - \\
\hline \multirow{4}{*}{ L2 } & $\begin{array}{l}\text { Prome } \\
\text { dio }\end{array}$ & $\begin{array}{c}6.5 \\
2\end{array}$ & $\begin{array}{c}8.9 \\
0\end{array}$ & $\begin{array}{c}50.8 \\
7\end{array}$ & $\begin{array}{c}23.0 \\
7\end{array}$ & $\begin{array}{c}86.17 \\
*\end{array}$ & 21.47 & 20.36 & 5.11 & 0.05 & 0.03 & 6.87 & 1.70 & \multirow{3}{*}{920} & \multirow{3}{*}{$\begin{array}{c}92 \\
0\end{array}$} & \multirow{3}{*}{28} \\
\hline & SD & 1.17 & $\begin{array}{c}3.5 \\
5\end{array}$ & 8.97 & 5.99 & $\begin{array}{c}29.43 \\
*\end{array}$ & 9.54 & 10.21 & 1.07 & 0.04 & 0.02 & 7.91 & 0.46 & & & \\
\hline & CV\% & $\begin{array}{l}17 . \\
93\end{array}$ & $\begin{array}{l}39 . \\
93\end{array}$ & $\begin{array}{c}17.6 \\
4\end{array}$ & $\begin{array}{c}25.9 \\
8\end{array}$ & $\begin{array}{c}34.15 \\
*\end{array}$ & 44.44 & 50.16 & 20.89 & 89.21 & 65.74 & 115.23 & 26.78 & & & \\
\hline & $\begin{array}{l}\text { ECA- } \\
\text { C4 }\end{array}$ & $\begin{array}{c}6,5 \\
- \\
9,0\end{array}$ & & $\begin{array}{c}1 \\
000\end{array}$ & - & $\leq 25$ & - & - & 13 & - & - & - & 5 & 1000 & - & - \\
\hline
\end{tabular}

*Valores que no cumplen con la norma reportados en la Categoría 4: Conservación del ambiente acuático de los Estándares Nacionales de Calidad Ambiental del Agua. Decreto Supremo Nº04-2017-MINAM. ECA-C4=Categoría 4 de los estándares de calidad ambiental.

Ll=Lago de Tunants; L2=Lago de Yahuahua. 

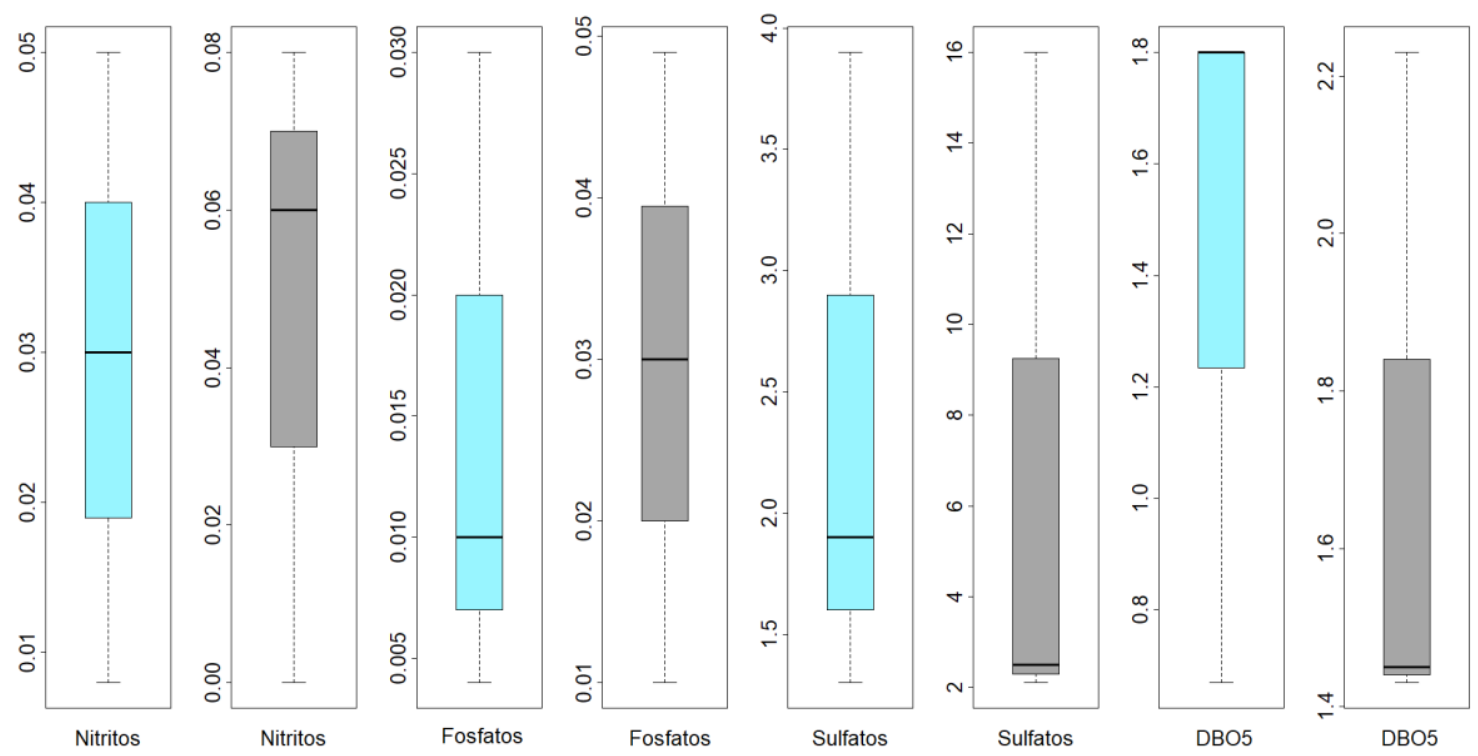

\section{$\begin{array}{cc}\text { Lago } & \text { Lago } \\ \text { Tunants } & \text { Yahuahua }\end{array}$}

Figura 4. Valores de las medianas de los parámetros Nitritos, Fosfatos, Sulfatos, $\mathrm{DBO}_{5}$.

\subsection{Correlación de los parámetros fisicoquímicos para el lago de Tunants}

En la figura "5 A", el pH, está fuertemente correlacionado de forma positiva con la turbidez, Ce, nitratos y sulfatos. Mientras que los parámetros de SST, dureza, fosfatos y $\mathrm{DBO}_{5}$, están correlacionado fuertemente de manera negativa. Los nitratos y nitritos, se correlaciona fuertemente de forma negativa con los sulfatos y $\mathrm{DBO}_{5}$.

Con respecto a la turbidez está fuertemente correlacionado de forma positiva con los parámetros de Ce, Nitratos y Sulfatos. Mientras que los parámetros moderadamente correlacionados son los SDT, Alcalinidad y fosfatos. Y los parámetros fuertemente correlacionados de forma negativa son los SST, Dureza, Nitritos y $\mathrm{DBO}_{5}$.

La Ce está fuertemente correlacionada de manera positiva con los nitratos y sulfatos. Mientras que los parámetros fuertemente correlacionados de manera negativa son, dureza, fosfatos y $\mathrm{DBO}_{5}$. El parámetro que no mostro una correlación lineal fue la alcalinidad. Con respecto a los SDT, están fuertemente correlacionados de manera positiva están los SST, 
alcalinidad y nitritos. Mientras que los parámetros moderadamente correlacionados de forma negativa son los nitratos y fosfatos. Y con una débil relación están los sulfatos.

Los SST, están fuertemente correlacionados de manera positiva con la alcalinidad, nitritos y $\mathrm{DBO}_{5}$. Mientras que los parámetros que están fuertemente correlacionado de manera negativa son los nitratos y sulfatos. Y los parámetros que muestran correlación moderada positiva son la dureza, fosfatos, alcalinidad. Los parámetros que muestran una débil relación negativa son los fosfatos y una relación débil positiva fue la dureza. Con respecto a la dureza está fuertemente correlacionada de manera positiva con los fosfatos y la $\mathrm{DBO}_{5}$. Y fuertemente correlacionado de manera negativa con los nitratos y sulfatos.

\subsection{Correlación de los parámetros fisicoquímicos para el lago de Yahuahua}

$\mathrm{El} \mathrm{pH}$, está fuertemente correlacionado de forma positiva con la $\mathrm{DBO}_{5}$ y los fosfatos. Y de manera negativa están la turbidez, Ce, SDT, SST, Alcalinidad, dureza, nitritos y sulfatos. Con respecto a la turbidez está fuertemente correlacionado de manera positiva con los SDT, SST, Alcalinidad, nitritos y sulfatos. Y de manera negativa están los fosfatos, el parámetro que muestra una débil correlación y de manera positiva es los nitritos.

La Ce, está fuertemente correlacionado de manera positiva con la alcalinidad, dureza, nitratos, nitritos. Y los parámetros que están correlacionados de manera negativa son los fosfatos y la $\mathrm{DBO}_{5}$. Con respecto a los SDT, los parámetros fuertemente correlacionados de manera negativa son los SST, alcalinidad y sulfatos. Mientras que de forma negativa están los fosfatos.

Los SST, están fuertemente correlacionados de manera positiva con la alcalinidad y sulfatos. Mientras que de manera negativa están correlacionados los fosfatos. Los parámetros de dureza y nitritos se encuentran correlacionados moderadamente de manera positiva.

La alcalinidad, están fuertemente correlacionados de manera positiva con la dureza y los nitritos. Mientras que están fuertemente correlacionados de manera negativa es los fosfatos y la $\mathrm{DBO}_{5}$. Por otro lado, la dureza se correlaciona fuertemente de manera positiva con los nitratos y nitritos. Así mismo tenemos a los fosfatos fuertemente correlacionados de manera positiva con la $\mathrm{DBO}_{5}$. 
REVISTA DE LA UNIVERSIDAD DEL ZULIA. 3ª época. Año 12 N 32, 2021

\begin{tabular}{|c|c|c|c|c|c|c|c|c|c|c|c|c|}
\hline $5 \mathrm{~A}$ & $\frac{T}{2}$ & 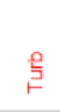 & ○ & 点 & 帛 & 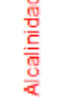 & 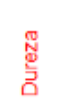 & 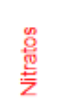 & 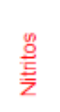 & 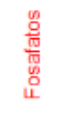 & 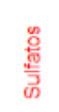 & 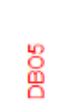 \\
\hline $\mathrm{pH}$ & 1 & 0.95 & 0.96 & & -0.73 & -0.3 & -0.99 & 0.97 & -0.69 & -0.87 & 1 & -0.95 \\
\hline Turb & 0.95 & 1 & 0.81 & -0.45 & -0.91 & -0.59 & -0.89 & 0.99 & -0.89 & -0.66 & 0.97 & -1 \\
\hline $\mathrm{Ce}$ & 0.96 & 0.81 & 1 & & -0.51 & & -0.99 & 0.87 & -0.46 & -0.98 & 0.93 & -0.82 \\
\hline SDT & & -0.45 & & 1 & 0.77 & 0.99 & & -0.35 & 0.81 & -0.37 & -0.22 & 0.43 \\
\hline SST & -0.73 & -0.91 & -0.51 & 0.77 & 1 & 0.87 & 0.62 & -0.87 & 1 & 0.3 & -0.79 & 0.91 \\
\hline Alcalinidad & -0.3 & -0.59 & & 0.99 & 0.87 & 1 & & -0.51 & 0.9 & & -0.38 & 0.58 \\
\hline Dureza & -0.99 & -0.89 & -0.99 & & 0.62 & & 1 & -0.93 & 0.58 & 0.93 & -0.97 & 0.9 \\
\hline Nitratos & 0.97 & 0.99 & 0.87 & -0.35 & -0.87 & -0.51 & -0.93 & 1 & -0.84 & -0.74 & 0.99 & -1 \\
\hline Nitritos & -0.69 & -0.89 & -0.46 & 0.81 & 1 & 0.9 & 0.58 & -0.84 & 1 & 0.25 & -0.75 & 0.88 \\
\hline Fosafatos & -0.87 & -0.66 & -0.98 & -0.37 & 0.3 & & 0.93 & -0.74 & 0.25 & 1 & -0.82 & 0.68 \\
\hline Sulfatos & 1 & 0.97 & 0.93 & & -0.79 & -0.38 & -0.97 & 0.99 & -0.75 & -0.82 & 1 & -0.98 \\
\hline DBO5 & -0.95 & -1 & -0.82 & 0.43 & 0.91 & 0.58 & 0.9 & -1 & 0.88 & 0.68 & -0.98 & 1 \\
\hline
\end{tabular}

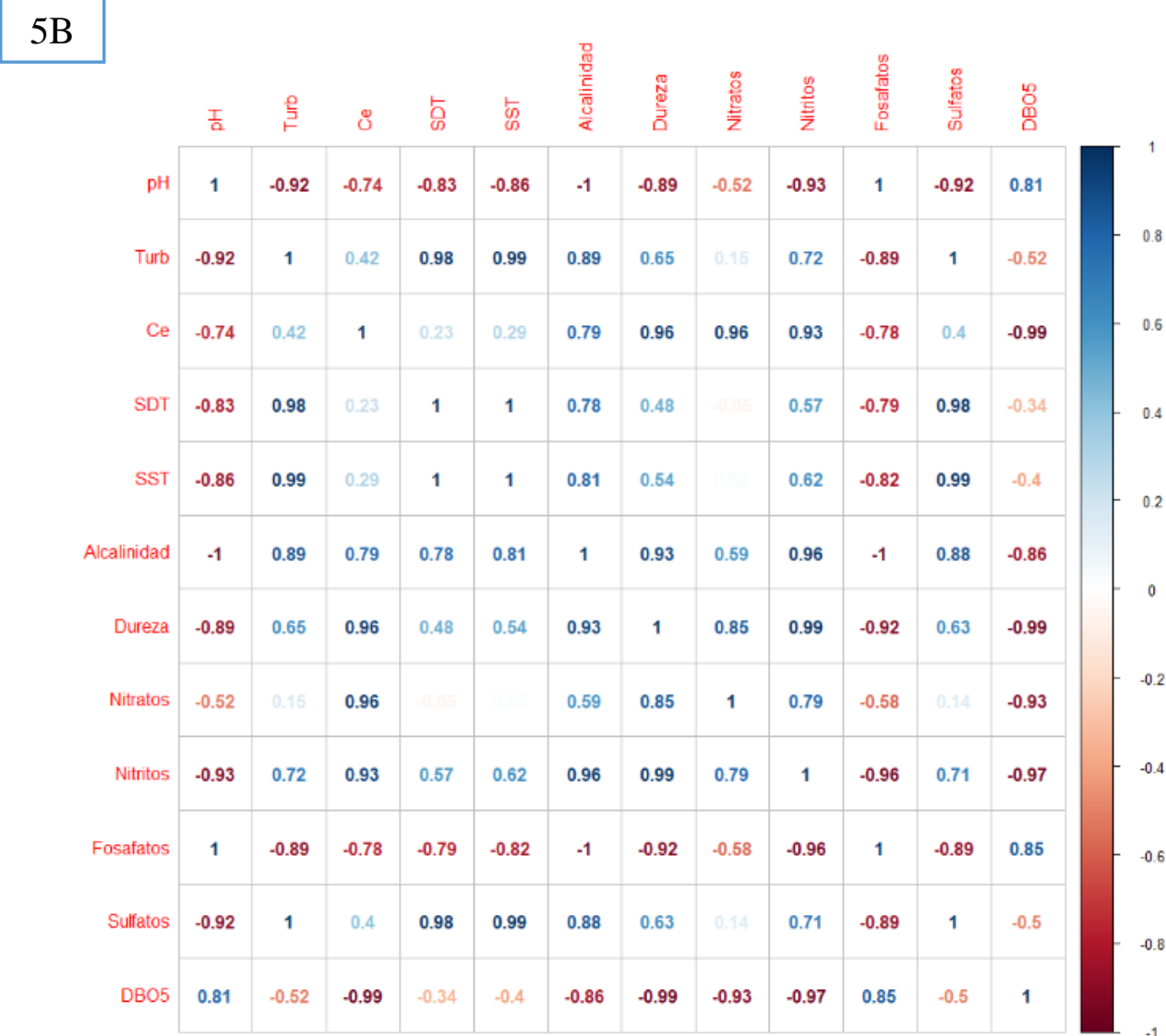

Figura 5. Correlación de los parámetros fisicoquímicos para el lago de Tunants (5A) y el lago de Yahuahua (5B). Nota: la puntuación para la correlación está basada en Ratner, (2009). Dónde: de 0 a 0,3 (0 y -0,3) débil relación ;0,3 y 0,7 (0,3 y 0.07) correlación moderada; 0,7 y l,0 (-0,7 y l,0) correlación fuerte. 


\subsection{Resultados de metales pesados para el lago de Tunants y Yahuahua}

El metal pesado que arrojó mayor concentración es el aluminio con 0.2385 ppm para el lago de Tunants. Mientras que en el lago de Yahuahua tuvo un valor de $0.1075 \mathrm{ppm}$. Con respecto al zinc para el lago de Tunants dio 0.0375 ppm, para el lago de Yahuahua 0.0285 ppm. El cobre es el metal que arrojó un valor de 0.02 ppm, en ambos lagos. (Figura 7).

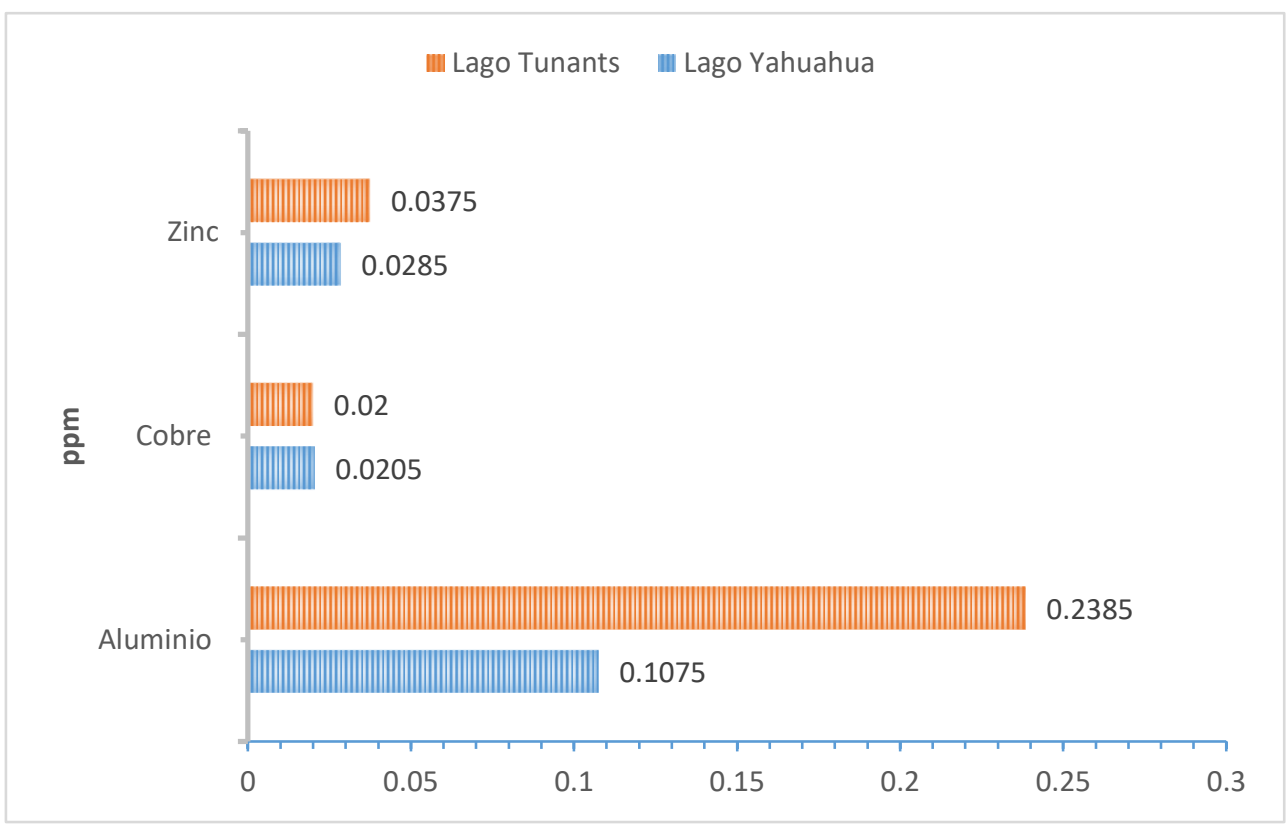

Figura 7. Relación de los metales pesados entre el lago de Tunants y Yahuahua.

\section{Discusión}

El pH, para el lago de Tunants y el lago de Yahuahua oscila entre 7.10 a 7, de acuerdo a los estándares de calidad ambiental (ECA), el pH se encuentra dentro del límite máximo permisible categoría 4 para aguas naturales superficiales que forman parte de ecosistemas frágiles, áreas naturales protegidas. Cuyas características para el "pH y la norma establecen" el valor recomendado mínimo de 6,5 y un máximo admisible de 9,0. Con respecto a la turbidez, para el lago de Tunants, el valor de la mediana fue de 7 UNT, encontrándose fuertemente correlacionado de forma positiva con los parámetros de Ce, Nitratos y Sulfatos. La mediana para el lago de Yahuahua, se encuentra a 7.95 UNT, por lo cual se puede evidenciar que tiene una turbidez elevada, en comparación con el valor de la Laguna Grande de San Pedro de Chile, cuya 
turbidez está comprendida entre 1.0 y 1.7 NTU, lo cual indica una reducida y homogénea turbidez del agua (Quintana, 2012). La Ce para el lago de Tunants arrojó una mediana de 60 $\mu \mathrm{S} / \mathrm{cm}^{2}$; mientras que para el lago de Yahuhua la Ce está en $54.8 \mu \mathrm{S} / \mathrm{cm}^{2}$. Las concentraciones de Ce se relacionan con el pH, cuando el pH es básico, la Ce arroja valores mínimos, condiciones ideales para el desarrollo de organismos (Morales et al, 2011).

Los SST para lago de Tunants arrojó una mediana de $106 \mathrm{mg} / \mathrm{L}$, para el lago de Yahuahua, se observa una mediana de $72 \mathrm{mg} / \mathrm{L}$, en ambos lagos existe una correlación moderada y positiva. Los SST, podrían estar asociados principalmente al arrastre de partículas de los canales de conducción que ingresa a los lagos (Espinal et al 2013). Su concentración puede evidenciar varios factores de alteración de las condiciones naturales de la misma. Por un lado, los procesos de erosión naturales se ven incrementados notablemente por diferentes causas de origen humano que provocan la falta de protección de los suelos, los que ocasionan grandes arrastres de materiales por escorrentía superficial en los fenómenos de fuertes precipitaciones (Villamarín et al., 2013).

Los SDT para el lago de Tunants tiene una mediana de $30.5 \mathrm{mg} / \mathrm{L}$. Mientras que para el lago Yahuahua la mediana está en $20.6 \mathrm{mg} / \mathrm{L}$. Ambos lagos tuvieron una correlación moderada. Mayormente el aumento de los SDT está dado por el arrastre de partícula hacia los lagos (Bohdziewicz, 2005). La alcalinidad tuvo una mediana de $32.2 \mathrm{ppm} \mathrm{CaCO}_{3}$ para el lago de Yahuahua, y el lago de Tunants dio un valor de 21.48 ppm $\mathrm{CaCO}_{3}$, mostrando una correlación positiva. Mientras que la dureza para ambos lagos tiene una mediana similar de $24.48 \mathrm{ppm}$ $\mathrm{CaCO}_{3}$ y muestran una correlación positiva. Los valores elevados de dureza y alcalinidad en los lagos podrían estar asociados al tipo de suelo en la zona, dado que predomina la arcilla, que está conformada de silicatos, magnesio, carbonatos y bicarbonatos (WHO, 2011).

Los fosfatos para el lago de Tunants evidencia una mediana de $0.01 \mathrm{ppm} \mathrm{PO}_{4}^{-}$. Correlacionado de forma moderada y positiva. Mientras que para el lago Yahuahua la mediana se encuentra en 0.03 ppm $\mathrm{PO}_{4}$ - y esta correlacionado de forma negativa. En ese sentido los fosfatos en los ambientes acuáticos, se debe a la descomposición de la materia biológica y la escorrentía de las actividades antrópicas. Comparando con el presente estudio, se afirma la presencia de fosfatos dado que los lugareños suelen practicar actividades domésticas de 
REVISTA DE LA UNIVERSIDAD DEL ZULIA. 3época. Año 12 № 32, 2021 Eli Morales Rojas et al. // Calidad físicoquímica y microbiológica del agua en los lagos ... 139-158

DOI: http://dx.doi.org/10.46925//rdluz.32.11

lavandería en los lagos. La presencia de fosfatos se relaciona directamente con la formación de macrofitas, que es común en los lagos, por la razón que suele operar como nutriente de crecimiento de algas (Rivas, 2009).

Para los nitratos la mediana en lago de Tunants se encuentra en 6.10 ppm $\mathrm{NO}_{3}$, en el lago de Yahuahua la mediana se muestra en 5.25 ppm $\mathrm{NO}_{3}$. Para ambos lagos se muestra una correlación fuertemente negativa. La presencia de los nitratos se podría deber a la gran cantidad de vegetación en los lagos, este elemento se libera por procesos de desnitrificación, al agua por el lavado de los suelos y es debido a su solubilidad en agua, aflorando en los lagos profundos (Keller, 1986). La mediana para los nitritos en lago de Tunants está 0.03 ppm $\mathrm{NO}_{2}$, y se correlaciona de forma negativa. Mientras que para el lago de Yahuhua la mediana se encuentra en 0.06 ppm $\mathrm{NO}_{2}$ correlacionada de forma moderada y positiva. El ion nitrito, se relaciona con los nitratos por su capacidad de convertirse de manera natural (Bolaños, 2017). En la zona de estudio podría estar influenciado por el mal manejo del alimento para peces y la falta de saneamiento. Los sulfatos para lago de Tunants se encuentra en $1.95 \mathrm{ppmSO}_{2}$, y para el lago de Yahuahua se encuentra en $2.5 \mathrm{ppmSO}_{2}$. Correlacionados en forma negativa. Los sulfatos suelen caracterizarse por ser muy abundantes en la naturaleza y su presencia en el agua varía de acuerdo a las condiciones del entorno (Bolaños, 2017).

Con respecto a la $\mathrm{DBO}_{5}$ la mediana para el lago de Tunants se encuentra en $1.8 \mathrm{mg} / \mathrm{L}_{\text {de }} \mathrm{O}_{5}$ y para el lago de Yahuahua la mediana se encuentra entre $1.45 \mathrm{mg} / \mathrm{L}$ de $\mathrm{O}_{2}$. Existiendo una correlación negativa para ambos lagos, se puede decir que no hay una alta concentración de materia orgánica en los lagos y está dentro de los estándares de calidad ambiental de la categoría 4, conservación del ambiente acuático. Los metales pesados están presentes en los lagos y fuentes naturales y antrópicas. Estos son los contaminantes ambientales más impactantes debido a su toxicidad, permanencia y tendencia a acumularse en los seres acuáticos (Rizzo, 2010). En los lagos evaluados se pudo encontrar concentración de aluminio con 0.2385 ppm, para el lago de Tunants, y en el lago de Yahuahua 0.1075 ppm. Con respecto al Zinc para el lago de Tunants 0.0375 ppm, para el lago de Yahuahua dio un valor 0.0285 ppm. El cobre es el metal que arrojó datos similares en ambos lagos con un valor de $0.02 \mathrm{ppm}$. La presencia de metales pesados en el agua es un asunto a investigar, dado que no hay efluentes industriales cercanos, sin embargo, 
REVISTA DE LA UNIVERSIDAD DEL ZULIA. 3a época. Año $12 \mathrm{~N}^{\circ}$ 32, 2021

Eli Morales Rojas et al. // Calidad físicoquímica y microbiológica del agua en los lagos ... 139-158

DOI: http://dx.doi.org/10.46925//rdluz.32.11

estudios mencionan que los metales pesados son desplazados de la tierra al agua y del agua a los seres vivos (Chen, et al 2000).

Con respecto a los parámetros microbiológicos, puede estar superditado a las descargas residuales, precipitaciones que generan arrastres contaminantes del suelo y que pueden contener carga microbiana, estos incrementan los niveles de microorganismos en el agua (Ortiz, 2016). En este caso se intuye que las precipitaciones juegan un papel importante en los resultados de CT (Cabrera et al., 2008). Dado que el presente estudio para el lago Tunants resulto tener mayor concentración de CT, >1600 NMP/100mL.

\section{Conclusiones}

Los valores de $\mathrm{pH}$ en los lagos Tunants $(7,17)$ y Yahuahua $(6,52)$ están correspondidos en los valores límites de los Estándares Nacionales de Calidad Ambiental del Agua 6,5- 9,0 y están altamente relacionados en positivo con los valores de nitratos.

La presencia de sulfatos y fosfatos, respondió a los coeficientes de variación más altos, valores relacionados con un aumento de la cantidad de detergentes en los lagos por el uso intensivo del agua en el uso doméstico y en la piscicultura.

El aluminio fue el metal pesado que se presentó en mayor concentración para ambos lagos, seguido del Zinc y Cobre. Al no haber efluentes industriales cercanos, estos metales pudieron haber sido desplazados desde la tierra al agua, alertándose que, del agua puede pasar a los seres vivos.

Todos los parámetros fisicoquímicos se encontraron dentro estándares de calidad del agua del Decreto Supremo N 004-2017-MINAM. Categoría 4: Conservación del ambiente acuático. Sin embargo, el único parámetro que no cumple con la norma fue los Sólidos Suspendidos Totales (SST).

Los análisis microbiológicos que resultó tener mayor concentración en CT, >1600 NMP/100mL, fue el lago de Tunants, también se evidenció la presencia de E. coli el cual indica que puede estar influenciado por heces de animales o humanos producto del arrastre de partículas ocasionado por las lluvias. 
REVISTA DE LA UNIVERSIDAD DEL ZULIA. 3aépoca. Año $12 \mathrm{~N}^{\circ}$ 32, 2021

Eli Morales Rojas et al. // Calidad físicoquímica y microbiológica del agua en los lagos ... 139-158

DOI: http://dx.doi.org/10.46925//rdluz.32.11

Referencias

Álvarez, J., Panta, J. E., Ayala, C. R., \& Acosta, E. H. (2008). Calidad integral del agua superficial en la cuenca hidrológica del Río Amajac. Información tecnológica, 19(6), 21-32. Doi: http://dx.doi.org/10.4067/S0718-07642008000600004

Agudelo, R. M. (2005). El agua, recurso estratégico del siglo XXI. Revista Facultad Nacional de Salud Pública, 23(1). https://revistas.udea.edu.co/index.php/fnsp/article/view/522

Bohdziewicz, J.; Sroka, E. Integrated system of activated sludge-reverse osmosis in the treatment of the wastewater the meat industry. Process Biochem. 40:1517-1523. (2005) Doi: https://doi.org/10.1016/j.procbio.2003.11.047

Bolaños-Alfaro, J. D., Cordero-Castro, G., \& Segura-Araya, G. (2017). Determinación de nitritos, nitratos, sulfatos y fosfatos en agua potable como indicadores de contaminación ocasionada por el hombre, en dos cantones de Alajuela (Costa Rica). Revista Tecnología en Marcha, 30(4), 1527. Doi: http://dx.doi.org/10.18845/tm.v30i4.3408

Chen, C. Y., Stemberger, R. S., Klaue, B., Blum, J. D., Pickhardt, P. C., \& Folt, C. L. (2000). Accumulation of heavy metals in food web components across a gradient of lakes. Limnology and Oceanography, 45(7), 1525-1536. Doi: https://doi.org/10.4319/lo.2000.45.7.1525

Cabrera, A., Pacheco, J. y Coronado, V. (2008) Presencia de organismos coliformes fecales en el agua subterránea de una granja porcícola en el Estado de Yucatán. Revista académica de la facultad de Ingeniería de la Universidad Autónoma de Yucatán Disponible en: http://www.bvsde.paho.org/bvsaidis/mexicoll/as-13.pdf

Dolbeth M., Pardal M.A., Lilleblo A.I., Azeiteiro U. \& Marques J.C. 2003. Short- and long-term effects of eutrophication on the secondary production of an intertidal macrobenthic community. Marine Biology. 10- 1007: 1133-1135. Doi: https://doi.org/10.1007/s00227-003-1133-5

Espinal Carreón, T., Sedeño Díaz, J. E., \& López López, E. (2013). Evaluación de la calidad del agua en la Laguna de Yuriria, Guanajuato, México, mediante técnicas multivariadas: un análisis de valoración para dos épocas 2005, 2009-2010. Revista internacional de contaminación ambiental, 29(3), 147-163.

Farnleitner, A. H. et al. Escherichia coli and enterococci are sensitive and reliable indicators for human, livestock and wildlife faecal pollution in alpine mountainous water resources. Journal of Applied Microbiology, 109(5): 1599-1608, 2010. Doi: https://doi.org/10.11l1/j.13652672.2010.04788.x

Fernández, A; Marín, J. C.; Ángel Corona, J. F.; González, I.; Perozo, R. (2017). Evolución en la morfología de la laguna Las Peonías: 1979-2016, Revista de la Universidad del Zulia, 8 (21), 41-59. 
REVISTA DE LA UNIVERSIDAD DEL ZULIA. 3a época. Año $12 \mathrm{~N}^{\circ}$ 32, 2021 Eli Morales Rojas et al. // Calidad físicoquímica y microbiológica del agua en los lagos ... 139-158

DOI: http://dx.doi.org/10.46925//rdluz.32.11

Gamarra Torres, O. A., Barrena Gurbillón, M. A., Barboza Castillo, E., Rascón Barrios, J., Corroto, F., \& Taramona Ruiz, L. A. (2018). Fuentes de contaminación estacionales en la cuenca del río Utcubamba, región Amazonas, Perú. Arnaldoa, 25(1), 179-194. Doi: http://dx.doi.org/http://doi.org/10.22497/arnaldoa.251.2511l

Harwood, V. J. et al. Validity of the indicator organism paradigm for pathogen reduction in reclaimed water and public health protection. Applied and Environmental Microbiology, $71(6)$ : 3163-3170, 2005. Doi: 10.1128/AEM.71.6.3163-3170.2005

Kazi T. G., Arain M. B., Jamali M. K., Jalbani N., Afridi H. I., Sarfraz R. A., Baig J. A. y Shah A. Q. (2009). Assessment of water quality of polluted lake using multivariate statistical techniques: a case study. Ecotoxicol. Environ. Saf. 72, 301-309. Doi: https://doi.org/10.1016/j.ecoenv.2008.02.024

Keller y J. R. Pitblade, "Water quality changes in Sudbury area lakes: a comparison of synoptic surveys in 1974-1976 and in 1981-1983", Water, Air and Soil Pollution, vol. 29, 1986, pp.285. Doi: https://doi.org/10.1007/BF00158760

León, V.L.F. (2006). Índices de calidad del agua (ICA), formas de estimarlos y aplicación en la cuenca Lerma-Chapala. México: Instituto Mexicano de Tecnología del Agua.

Luna Pabello, V. M. y Aburto Castañeda, S. Sistema de humedales artificiales para el control de la eutroficación del lago del Bosque de San Juan de Aragón. Tip Revista Especializada en Ciencias Químico-Biológicas, 17(1): 32-55, 2014.

Morales, R. H., Ortega, M. R., Sánchez, J. D., Alvarado, R., \& Aguilera, M. S. (2011). Distribución estacional del fitoplancton en un lago cálido monomíctico en Michoacán, México. Biológicas Revista de la DES Ciencias Biológico Agropecuarias, 13(2), 21-28.

Madera, L. C., Angulo, L. C., Díaz, L. C., \& Rojano, R. (2016). Evaluación de la Calidad del Agua en Algunos Puntos Afluentes del río Cesar (Colombia) utilizando Macroinvertebrados Acuáticos como Bioindicadores de Contaminación. Información tecnológica, 27(4), 103-110. Doi: http://dx.doi.org/10.4067/S0718-07642016000400011

Ortiz, J. C., Tafur, D. L., \& Corroto, F. (2016). Caracterización fisicoquímica y microbiológica de las aguas residuales en la ciudad de Chachapoyas, Región Amazonas. Ciencia Amazónica:(Iquitos), 6(1), 16-27.

OMS (Organización Mundial de Salud, US). 2006. Agua, saneamiento y salud: Enfermedades relacionadas con el agua.

Perez, A., \& Rodriguez, A. (2008). Indice fisicoquimico de la calidad de agua para el manejo de lagunas tropicales de inundacion. Costa Rica: Revista SciELO. 
REVISTA DE LA UNIVERSIDAD DEL ZULIA. 3época. Año 12 № 32, 2021

Eli Morales Rojas et al. // Calidad físicoquímica y microbiológica del agua en los lagos ... 139-158

DOI: http://dx.doi.org/10.46925//rdluz.32.11

Pinilla G. 2000. Indicadores Biológicos en Ecosistemas Acuáticos Continentales de Colombia. Compilación Bibliográfica. Fundación Universidad de Bogotá Jorge Tadeo Lozano. Centro de Investigaciones Científicas. Santafé de Bogotá, Colombia.

PNUMA (2008). Water Quality for Ecosystems and Human Health. 2ae ed. PNUMA, ERCE, UNESCO.

Quintana-Sotomayor, C., Lillo-Saavedra, M., Gonzalo-Martín, C., \& Barrera-Berrocal, J. A. (2012). Metodología para estimación de la turbidez de un lago mediante la clasificación orientada a objetos de imágenes multiespectrales. Tecnología y ciencias del agua, 3(4), 143-150.

Rengifo, D., \& Reyes, W. (2017). Amazonía peruana en riesgo por presencia de mercurio en el río Napo. Revista Ciencia y Tecnología, 12(3), 41-50.

Rizzo, A., Daga, R., Arcagni, M., Perez, S., Bubach, D., Sánchez, R., ... \& Arribére, M. A. (2010). Concentraciones de metales pesados en distintos compartimentos de lagos andinos de Patagonia Norte. Ecología austral, 20(2), 155-171.

Rivas, Z., Sánchez, J., Troncone, F., Márquez, R., Ledo de Medina, H., Colina, M., \& Gutiérrez, E. (2009). Nitrógeno y fósforo totales de los ríos tributarios al sistema Lago de Maracaibo, Venezuela. Interciencia, 34(5), 308-314.

Rivera-Jacinto, M., Rodríguez-Ulloa, C., \& López-Orbegoso, J. (2009). Contaminación fecal en hortalizas que se expenden en mercados de la ciudad de Cajamarca, Perú. Revista Peruana de Medicina Experimental y Salud Pública, 26(1), 45-48.

Ruiz, N. E. S., Escobar, Y. C., \& Escobar, J. C. (2007). Revisión de parámetros fisicoquímicos como indicadores de calidad y contaminación del agua. Ingeniería e Investigación, 27(3), 172-181.

R Core Team. R: A Language and Environment for Statistical Computing. R Foundation for Statistical Computing, Vienna, Austria. Retrieved from, 2020. https://www.r-project.org/.

Ratner, B. (2009). The correlation coefficient: Its values range between $+1 /-1$, or do they? Journal of targeting, measurement and analysis for marketing, 17(2), 139-142. Doi: https://doi.org/10.1057/jt.2009.5

Villamarín, C., Rieradevall, M., Paul, M. J., Barbour, M. T., \& Prat, N. (2013). A tool to assess the ecological condition of tropical high Andean streams in Ecuador and Peru: The IMEERA index. Ecological indicators, 29, 79-92. Doi: https://doi.org/10.1016/j.ecolind.2012.12.006

Wen-Cheng L., Hwa-Lung Y. y Chung-En C. (2011). Assessment of water quality in a subtropical alpine Lake using multivariate statistical techniques and geostatistical mapping: A case study. Int. J. Environ. Res. Public Health 8, 1126-1140. Doi: https://doi.org/10.3390/ijerph8041126 
REVISTA DE LA UNIVERSIDAD DEL ZULIA. 3época. Año $12 \mathrm{~N}^{\circ}$ 32, 2021 Eli Morales Rojas et al. // Calidad físicoquímica y microbiológica del agua en los lagos ... 139-158

World Health Organization (WHO). (2011). Hardness in drinking-water. Documento de referencia para la elabo־ración de las Guías de la OMS para la calidad del agua potable. (WHO/SDE/WSH/03.04/6).

[en línea] www.who.int/water_sanitation_health/dwq/chemicals/ hardness.pdf

http://

\section{ANEXOS}

Anexo 1. Lago de Yahuahua (A), Realizan actividades del lavado de ropa y recreación (B).
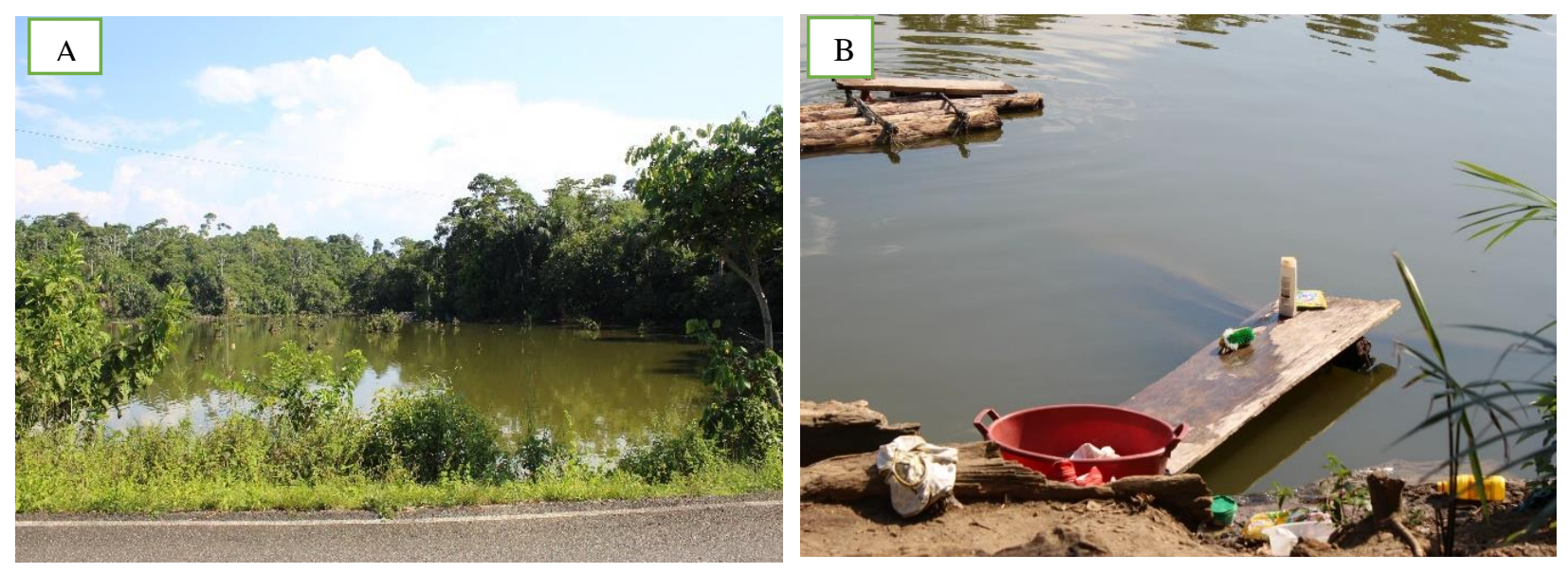

Anexo 2. Lago de Tunants

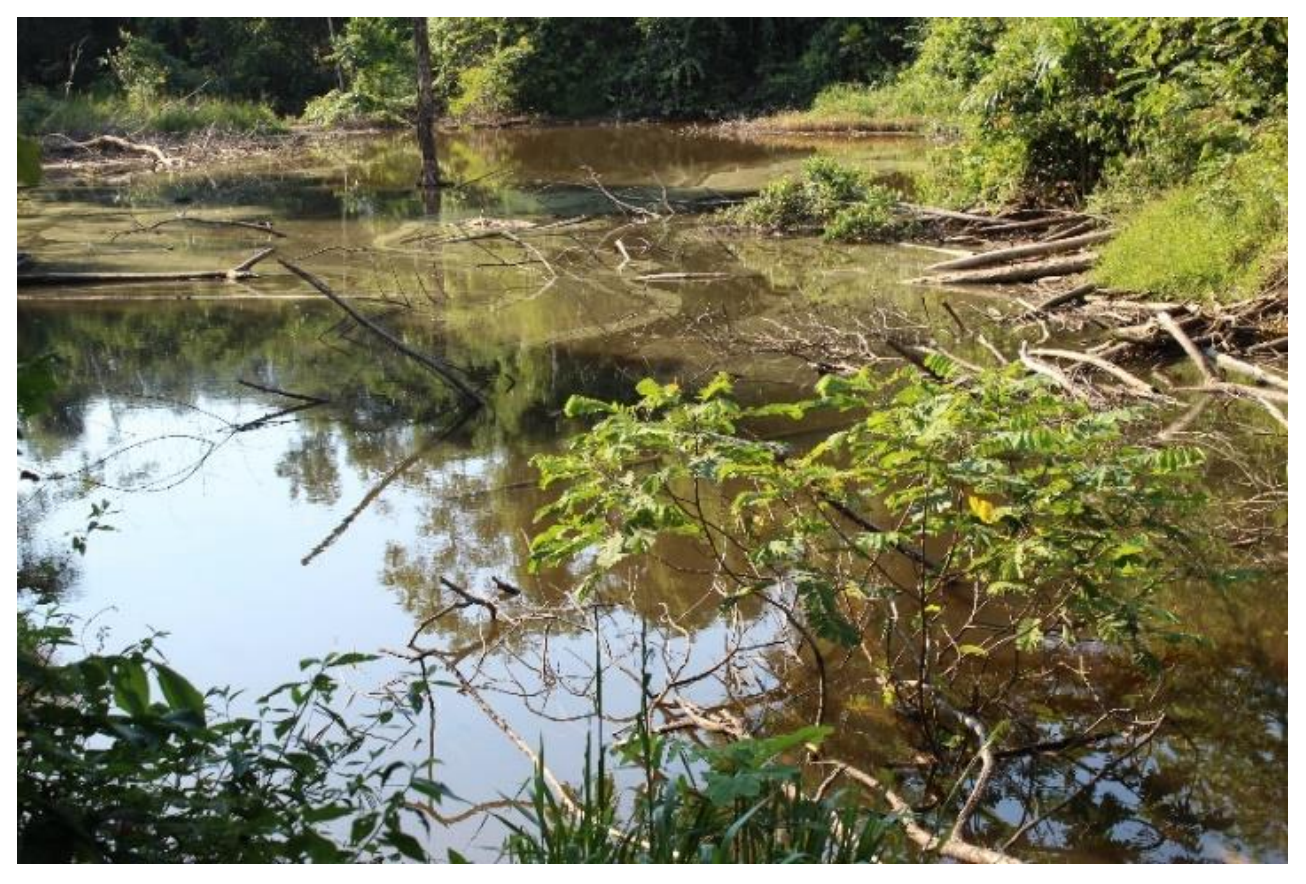

